\title{
Improved Method for Analyzing Ignition Data from the Cone Calorimeter in the Vertical Orientation
}

\author{
MARC L. JANSSENS \\ Southwest Research Institute \\ Department of Fire Technology \\ 6220 Culebra \\ San Antonio, TX 78238 \\ USA \\ (210) 522-6655 \\ marc. janssens@swri.edu
}

\begin{abstract}
Extensive research has been conducted on the use of the Cone Calorimeter to obtain flammability properties of materials for modeling. Ignition properties such as surface temperature at ignition $\left(T_{\mathrm{ig}}\right)$ and thermal inertia $(k \rho c)$ are typically determined on the basis of piloted ignition times measured at different heat flux levels. A specific functional relationship between piloted ignition time and heat flux is used to correlate the data and estimate the material properties. The functional relationship is based on the solution of a simplified form of the heat conduction problem in the Cone Calorimeter. Previous ignition studies have always assumed that the surface heat losses involve Newtonian cooling, which is characterized by a constant convection coefficient. However, earlier measurements obtained by the author show that the convection coefficient in the Cone Calorimeter for specimens in the vertical orientation could be more appropriately expressed as a quadratic function of the heat flux. This paper presents the experimental data and analysis that resulted in this proposed quadratic relationship. The solution of the modified conduction model is derived, and its use for the analysis of ignition data is illustrated for six solid wood species.
\end{abstract}

KEYWORDS: Cone calorimeter, ignition temperature, fire modeling, thermal inertia

\section{INTRODUCTION}

The standard procedure for obtaining ignition properties of a material involves a series of tests to measure the time to piloted ignition at different heat fluxes over the range of exposure conditions of interest. Many investigators have used the Cone Calorimeter [1] to obtain this kind of data. Based on extensive numerical heat transfer calculations and a surface temperature criterion for ignition, Janssens has shown that the following relationship can be established between the incident heat flux, $\dot{q}_{e}$, and the time to ignition, $t_{\mathrm{ig}}$, for a thermally thick solid [2]:

$$
\dot{q}_{e}=\dot{q}_{c r}\left[1+A\left(\frac{k \rho c}{h_{i g}^{2} t_{i g}}\right)^{a}\right]
$$

FIRE SAFETY SCIENCE--PROCEEDINGS OF THE SEVENTH INTERNATIONAL SYMPOSIUM, pp. 803-814 
where

$$
\begin{array}{ll}
\dot{q}_{e}^{\prime \prime} & =\text { incident heat flux }\left(\mathrm{kW} / \mathrm{m}^{2}\right) \\
\dot{q}_{c r}^{\prime \prime} & =\text { critical heat flux for piloted ignition, see below }\left(\mathrm{kW} / \mathrm{m}^{2}\right) \\
A & =\text { constant } \\
a & =\text { constant } \\
k \rho c & =\text { thermal inertia }\left(\mathrm{kW}^{2} \cdot \mathrm{s} / \mathrm{m}^{4} \cdot \mathrm{K}^{2}\right) \\
h_{\text {ig }} & =\text { surface heat transfer coefficient at ignition }\left(\mathrm{kW} / \mathrm{m}^{2} \cdot \mathrm{K}\right) \\
t_{\text {ig }} & =\text { time to ignition }(\mathrm{s})
\end{array}
$$

The best agreement between Eq. 1 and the numerical calculations was obtained for $A=$ 0.73 and $a=0.547$. $A=0.71$ and $a=0.5$ gave a slightly inferior fit. The critical heat flux for ignition is the theoretical maximum heat flux below which ignition cannot occur, regardless of the duration of exposure. $\dot{q}_{c r}$ can be obtained from the following steadystate heat balance at the surface of the specimen:

$$
\varepsilon \dot{q}_{c r}^{\prime \prime}=h_{c}\left(T_{i g}-T_{\infty}\right)+\varepsilon \sigma\left(T_{i g}^{4}-T_{\infty}^{4}\right) \equiv h_{i g}\left(T_{i g}-T_{\infty}\right)
$$

where

$$
\begin{array}{ll}
\varepsilon & =\text { surface emissivity } \\
h_{\mathrm{c}} & =\text { convective heat transfer coefficient }\left(\mathrm{kW} / \mathrm{m}^{2} \cdot \mathrm{K}\right) \\
T_{\mathrm{ig}} & =\text { surface temperature at ignition }\left({ }^{\circ} \mathrm{C} \text { or K}\right) \\
T_{\infty} & =\text { ambient temperature at ignition }\left({ }^{\circ} \mathrm{C} \mathrm{or} \mathrm{K}\right) \\
\sigma & =\text { Boltzmann constant }\left(5.67 \times 10^{-11} \mathrm{~kW} / \mathrm{m}^{2} \cdot \mathrm{K}^{4}\right)
\end{array}
$$

Equation 1 is based on the assumption that the surface heat losses involve Newtonian cooling, which is characterized by a constant convection coefficient. Janssens et al. recently showed that the convection coefficient in the Cone Calorimeter in the horizontal orientation can be represented by a piece-wise linear function of the incident heat flux [3]. The modified conduction equation that accounts for this relationship was solved and a new functional relationship to correlate piloted ignition data was derived. Use of the functional relationship was illustrated with an analysis of ignition data obtained for red oak and glassfiber-reinforced polyester.

Janssens also characterized the thermal environment in the Cone Calorimeter in the vertical orientation (see [4], pp. 4.106-4.108). Although the convection coefficient appeared to vary between 0.009 and $0.027 \mathrm{~kW} / \mathrm{m}^{2} \cdot \mathrm{K}$ at incident heat fluxes of 20 and 60 $\mathrm{kW} / \mathrm{m}^{2}$ respectively, Janssens used an average value of $0.0135 \mathrm{~kW} / \mathrm{m}^{2} \cdot \mathrm{K}$ for subsequent analyses. This paper revisits Janssens' earlier measurements and develops an improved procedure for correlating ignition data from the Cone Calorimeter in the vertical orientation, which accounts for the effect of heat flux on the convection coefficient. The approach is similar to that presented in reference [3] for the horizontal orientation. 


\section{CONVECTION HEAT TRANSFER MEASUREMENTS}

\section{General Approach}

The convective heat transfer coefficient, $h_{c}$, for materials tested vertically in the Cone Calorimeter with the sample retainer frame was determined by exposing a piece of calcium silicate $(\mathrm{Ca}-\mathrm{Si})$ board to the radiant flux of the cone heater and measuring the temperatures of the exposed and unexposed surfaces. The temperatures of the two surfaces were used to calculate the net heat flux into the calcium silicate board, $\dot{q}_{n e t}$, as a function of time using a finite difference method along with material properties provided by the manufacturer of the board. The net heat flux was then used to calculate the convective heat transfer coefficient based on a heat balance at the exposed surface:

where

$$
h_{c}=\frac{\varepsilon \dot{q}_{e}^{\prime \prime}-\varepsilon \sigma\left(T_{s}^{4}-T_{\infty}^{4}\right)-\dot{q}_{n e t}^{\prime \prime}}{\left(T_{S}-T_{\infty}\right)}
$$

$T_{\mathrm{s}} \quad=$ surface temperature $\left({ }^{\circ} \mathrm{C}\right.$ or $\left.\mathrm{K}\right)$

$\dot{q}_{\text {net }}^{\prime \prime} \quad=$ net heat flux into the specimen $\left(\mathrm{kW} / \mathrm{m}^{2}\right)$

\section{Experimental Details}

The test specimen was a $100 \times 100 \mathrm{~mm} \times 12.7 \mathrm{~mm}$ thick piece of "Marinite I" calcium silicate board. A $0.13 \mathrm{~mm}$ diameter, type K, thermocouple (TC) was used to measure the exposed surface temperature. The TC was fixed to the board by drilling small holes through the board approximately $13 \mathrm{~mm}$ on either side of the center (along the diagonal) and running the TC wires through the holes with the TC bead held securely against the sample surface. A $0.13 \mathrm{~mm}$ diameter type $\mathrm{K}$ thermocouple was also attached to the bottom surface of the specimen to measure the unexposed surface temperature. The test specimen was backed with refractory blanket and placed in the standard vertical Cone Calorimeter sample holder. The specimen was exposed to radiant heat fluxes of 20, 40, and $60 \mathrm{~kW} / \mathrm{m}^{2}$, until the surface temperature reached a steady state.

\section{Surface Emissivity}

To calculate the convective heat transfer coefficient using Eq. 3, the surface emissivity, $\varepsilon$, of the Ca-Si board is required. Because no data could be found in the literature, the emissivity was measured on the basis of a comparison between thermocouple and infrared pyrometer measurements of surface temperature of a heated sample. The results of these measurements are presented in reference [3]. The results indicate that the average surface emissivity for Marinite I calcium silicate board is 0.88 over a temperature range between 40 and $700^{\circ} \mathrm{C}$.

\section{Results}

The measured temperatures of the exposed and unexposed surfaces of the Ca-Si board were used to calculate the net heat flux and the associated convective heat transfer 
coefficient as a function of time according to Eq. 3. Average $h_{c}$ values of $0.0039,0.0093$, and $0.0171 \mathrm{~kW} / \mathrm{m}^{2} \cdot \mathrm{K}$ were obtained for incident heat fluxes of 20,40 , and $60 \mathrm{~kW} / \mathrm{m}^{2}$ respectively. The data are presented with respect to the external heat flux in Fig. 1. The following quadratic expression was developed for the convective heat transfer coefficient:

$$
h_{c}=1.4 \cdot 10^{-4} \dot{q}_{e}^{\prime \prime}+2.4 \cdot 10^{-6}\left(\dot{q}_{e}^{\prime \prime}\right)^{2}
$$

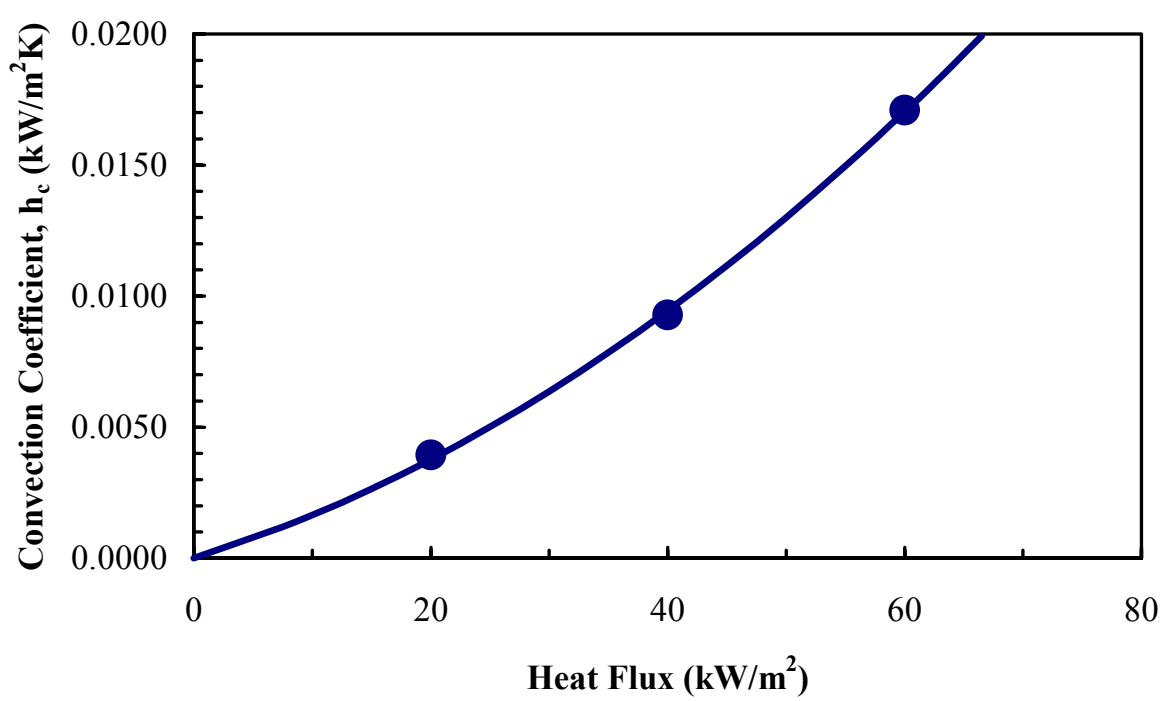

Fig. 1. Convection coefficient as a function of heat flux.

\section{CONVECTION HEAT TRANSFER CALCULATIONS}

Correlations presented in Tables 1-3.3 and 1-3.4 of the SFPE Handbook [5] were used to calculate the average convection coefficient for forced and free flow over a $0.1 \mathrm{~m}$ long isothermal flat plate respectively. The resulting values as a function of surface temperature are shown in Fig. 2. The convection coefficient for free flow conditions ranges from approximately $0.0022 \mathrm{~kW} / \mathrm{m}^{2} \cdot \mathrm{K}$ at $T_{\mathrm{s}}=25^{\circ} \mathrm{C}$ to $0.0063 \mathrm{~kW} / \mathrm{m}^{2} \cdot \mathrm{K}$ at $T_{\mathrm{s}}=$ $400^{\circ} \mathrm{C}$. The forced flow calculations were performed for free-stream velocities of 1,3 , and $5 \mathrm{~m} / \mathrm{s}$. It can be seen that the corresponding $h_{\mathrm{c}}$ values are nearly independent of $T_{\mathrm{s}}$, and are approximately equal to $0.012,0.021$, and $0.027 \mathrm{~kW} / \mathrm{m}^{2} \cdot \mathrm{K}$ respectively. Although these calculations are not entirely valid for a plate that has the same width as its length, the results seem to indicate that the convection heat transfer is forced rather than free. In other words, the flow is driven by the heater, which explains the heat flux dependency of $h_{\mathrm{c}}$. 


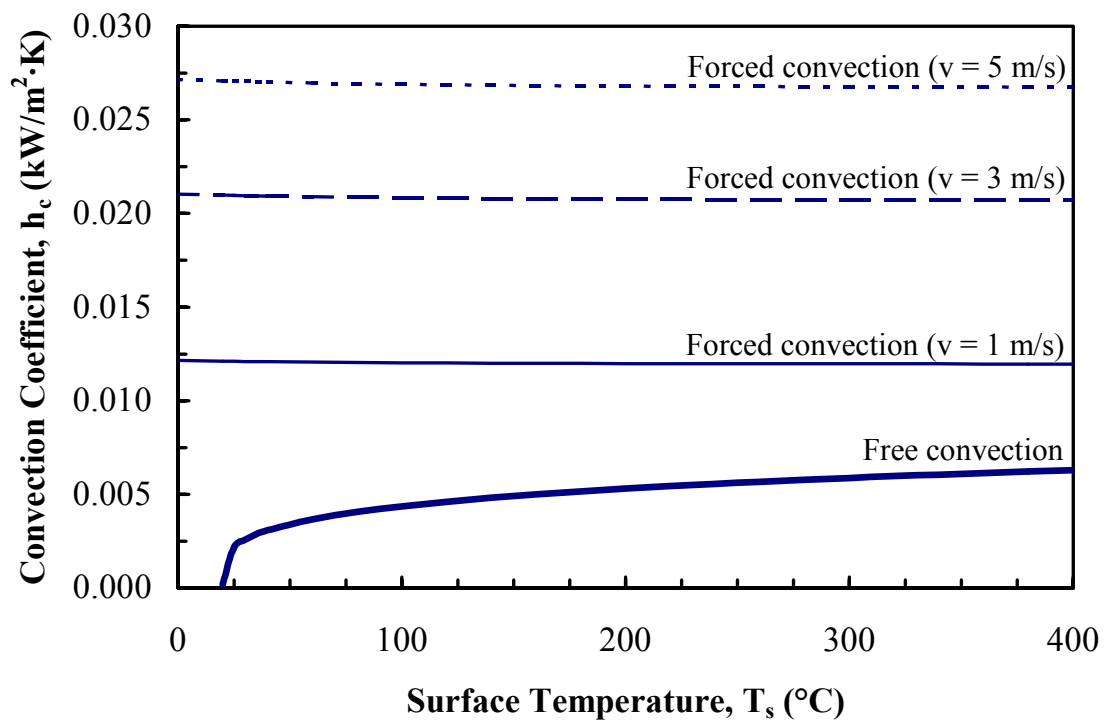

Fig. 2. Convection Heat Transfer Calculations.

\section{IMPLICATIONS FOR ANALYSIS OF PILOTED IGNITION DATA}

Based on a constant value of $h_{\mathrm{c}}$, Eq. 1 suggests plotting $\left(1 / t_{\mathrm{ig}}\right)^{\mathrm{a}}$ as a function of $\dot{q}_{e}^{\prime \prime}$. The intercept of a straight-line fit through the data points and the abscissa (heat flux) is the best estimate of $\dot{q}_{c r}^{\prime \prime}$. $T_{\text {ig }}$ can be calculated from $\dot{q}_{c r}^{\prime \prime}$ by solving Eq. 2. Finally, the $k \rho c$ is calculated from the slope of the straight-line fit through the data points. This procedure has been applied with reasonable success to wood products and plastics [2][6]. How is this procedure affected by the fact that $h_{\mathrm{c}}$ varies with $\dot{q}_{e}^{\prime \prime}$ ? This is the fundamental question that is addressed in this section.

Eq. 4 can be written in generic form as:

$$
h_{c} \equiv h_{1} \dot{q}_{e}^{\prime \prime}+h_{2}\left(\dot{q}_{e}^{\prime \prime}\right)^{2}
$$

where $\mathrm{h}_{1}=1.4 \cdot 10^{-4} 1 / \mathrm{K}$ and $\mathrm{h}_{2}=2.4 \cdot 10^{-6} \mathrm{~m}^{2} / \mathrm{kW} \cdot \mathrm{K}$.

Substituting Eq. 2 for $\dot{q}_{c r}^{\prime}$, Eq. 1 with $\mathrm{A}=0.71$ and $a=0.5$ can be written as

$$
\dot{q}_{e}^{\prime \prime}=\sigma\left(T_{i g}^{4}-T_{\infty}^{4}\right)+\frac{h_{c}}{\varepsilon}\left(T_{i g}-T_{\infty}\right)+\frac{0.71\left(T_{i g}-T_{\infty}\right)}{\varepsilon}\left(\frac{k \rho c}{t_{i g}}\right)^{0.5}
$$

Substitution of Eq. 5 into Eq. 6, after rearranging, leads to 
where

$$
\left(\frac{k \rho c}{t_{i g}}\right)^{0.5}=C_{0}+C_{1} \dot{q}_{e}^{\prime \prime}+C_{2}\left(\dot{q}_{e}^{\prime \prime}\right)^{2}
$$

$$
\begin{gathered}
C_{0}=-\frac{\varepsilon \sigma\left(T_{i g}^{4}-T_{\infty}^{4}\right)}{0.71\left(T_{i g}-T_{\infty}\right)} \\
C_{1}=\frac{\varepsilon}{0.71\left(T_{i g}-T_{\infty}\right)}-\frac{h_{1}}{0.71}
\end{gathered}
$$

and

$$
C_{2}=-\frac{h_{2}}{0.71}
$$

Equation 7 a still suggests that $\left(1 / t_{\mathrm{ig}}\right)^{0.5}$ be plotted as a function of $\dot{q}_{e}^{\prime \prime}$. The smallest root of the quadratic equation on the right-hand side of Eq. 7a is equal to $\dot{q}_{c r}^{\prime \prime}$ :

$$
\dot{q}_{c r}^{\prime \prime}=\frac{-C_{1}+\sqrt{C_{1}^{2}-4 C_{0} C_{2}}}{2 C_{2}}
$$

This relationship, in conjunction with Eqs. $7 \mathrm{~b}-7 \mathrm{~d}$ can be used to determine $T_{\text {ig. }}$. Once the surface temperature at ignition is known, $k \rho c$ can be calculated from the best fit of a second order polynomial through the data points according to Eq. 7a..

\section{SAMPLE APPLICATION OF THE REVISED IGNITION DATA ANALYSIS}

\section{Materials Tested}

The time to piloted ignition was measured for vertical oven dry samples of six wood species in the Cone Calorimeter at heat fluxes between 15 and $45 \mathrm{~kW} / \mathrm{m}^{2}$. Table 1 gives some information about the species that were tested. The first four species are softwoods, the remaining two are hardwoods. Western red cedar, redwood, and Douglas fir are North American species, and the remaining species are Australian.

\section{Results and Correlations}

The measured ignition times are presented in Table 2. Correlations of the results according to the procedure outlined in the previous section are presented in Figs. 3-8. The polynomial fit in each figure has a very slight curvature. The gray circles are outlying data points. The two measurements for radiata pine at $35 \mathrm{~kW} / \mathrm{m}^{2}$ and one data point for Victorian ash at $20 \mathrm{~kW} / \mathrm{m}^{2}$ were omitted from the analysis because they are outside the $95 \%$ confidence limits. 
Table 1. Wood species tested

\begin{tabular}{|l|c|c|}
\hline Species & Density, $\rho\left(\mathbf{k g} / \mathbf{m}^{\mathbf{3}}\right)$ & Thickness, $\boldsymbol{L}(\mathbf{m m})$ \\
\hline Western red cedar & 330 & 17.0 \\
Redwood & 430 & 19.0 \\
Radiata pine & 460 & 17.5 \\
Douglas fir & 465 & 16.8 \\
Victorian ash & 640 & 17.2 \\
Blackbutt & 810 & 17.4 \\
\hline
\end{tabular}

The corresponding ignition properties are given in Table 3 . The emissivity of wood was taken to be 0.88 [2]. Some samples were instrumented with surface thermocouples. The ranges of measured ignition temperatures reported in [4] are also given in Table 3. The last column in Table 3 lists $k \rho c$ values at a temperature halfway between $T_{\infty}$ and $T_{\text {ig, }}$, based on thermal physical data for wood in the literature [7][8][9]

Table 2. Measured ignition times

\begin{tabular}{|c|c|c|c|c|c|}
\hline \multicolumn{2}{|c|}{ Western red cedar } & \multicolumn{2}{c|}{ Redwood } & \multicolumn{2}{c|}{ Radiata pine } \\
\hline $\begin{array}{c}\text { Heat Flux } \\
\mathrm{kW} / \mathrm{m}^{2}\end{array}$ & $\begin{array}{c}\mathrm{t}_{\mathrm{ig}} \\
(\mathrm{s})\end{array}$ & $\begin{array}{c}\text { Heat Flux } \\
\mathrm{kW} / \mathrm{m}^{2}\end{array}$ & $\begin{array}{c}\mathrm{t}_{\mathrm{ig}} \\
(\mathrm{s})\end{array}$ & $\begin{array}{c}\text { Heat Flux } \\
\mathrm{kW} / \mathrm{m}^{2}\end{array}$ & $\begin{array}{c}\mathrm{t}_{\mathrm{ig}} \\
(\mathrm{s})\end{array}$ \\
\hline 15.0 & 620.4 & 20.0 & 576.2 & 20.0 & 139.7 \\
20.0 & 223.4 & 25.0 & 101.1 & 25.0 & 56.2 \\
25.0 & 57.6 & 25.0 & 132.6 & 25.0 & 64.0 \\
25.0 & 48.0 & 30.0 & 37.7 & 30.0 & 49.4 \\
30.0 & 23.2 & 30.0 & 41.7 & 30.0 & 46.6 \\
30.0 & 23.3 & 35.0 & 32.4 & 35.0 & 37.2 \\
35.0 & 17.0 & 35.0 & 28.0 & 35.0 & 37.6 \\
35.0 & 19.2 & 40.0 & 21.4 & 40.0 & 17.8 \\
\hline \multicolumn{2}{|c|}{ Douglas fir } & \multicolumn{2}{|c|}{ Victorian ash } & \multicolumn{2}{c|}{ Blackbutt } \\
\hline Heat Flux & $\mathrm{t}_{\mathrm{ig}}$ & Heat Flux & $\mathrm{t}_{\mathrm{ig}}$ & Heat Flux & $\mathrm{t}_{\mathrm{ig}}$ \\
$\mathrm{kW} / \mathrm{m}^{2}$ & $(\mathrm{~s})$ & $\mathrm{kW} / \mathrm{m}^{2}$ & $(\mathrm{~s})$ & $\mathrm{kW} / \mathrm{m}^{2}$ & $(\mathrm{~s})$ \\
\hline 20.0 & 201.0 & 20.0 & 322.4 & 20.0 & 203.8 \\
25.0 & 76.2 & 25.0 & 84.2 & 25.0 & 96.3 \\
25.0 & 70.1 & 25.0 & 86.0 & 25.0 & 124.6 \\
30.0 & 44.2 & 30.0 & 38.8 & 30.0 & 60.8 \\
30.0 & 43.0 & 30.0 & 42.4 & 30.0 & 57.0 \\
35.0 & 31.6 & 35.0 & 32.0 & 35.0 & 39.5 \\
35.0 & 29.0 & 35.0 & 31.1 & 35.0 & 47.0 \\
40.0 & 22.7 & 40.0 & 23.1 & 40.0 & 30.7 \\
\hline
\end{tabular}




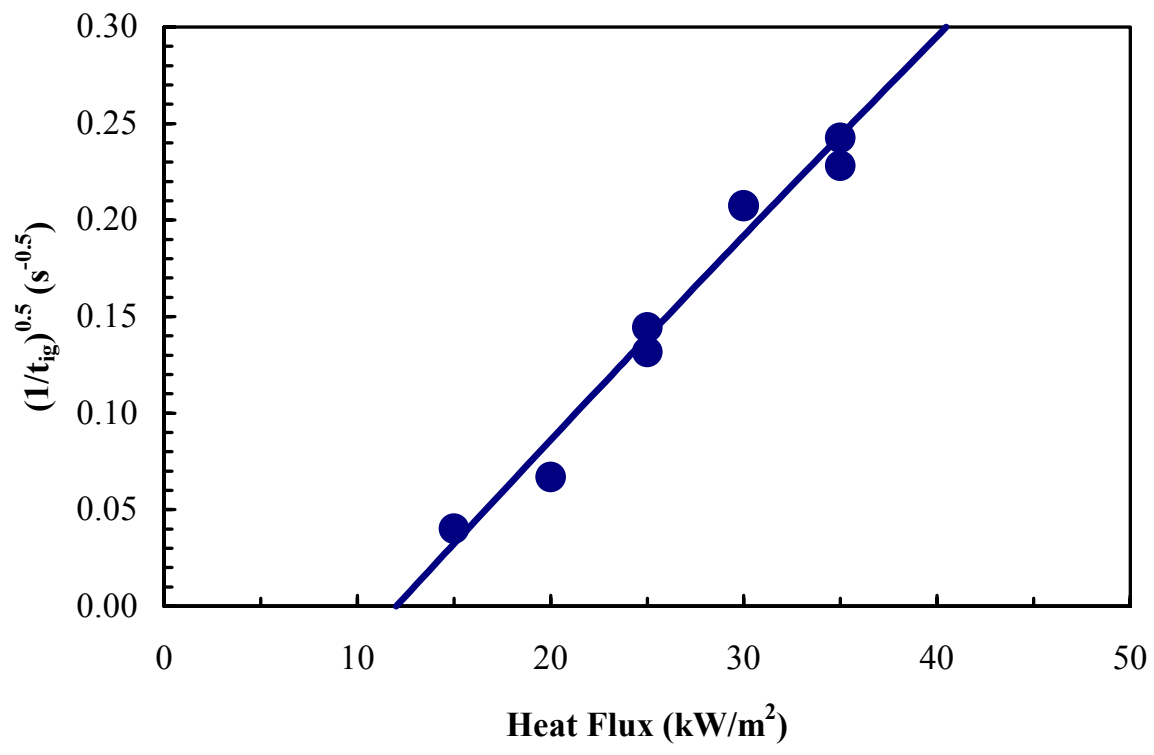

Fig. 3. Correlation of ignition data for western red cedar

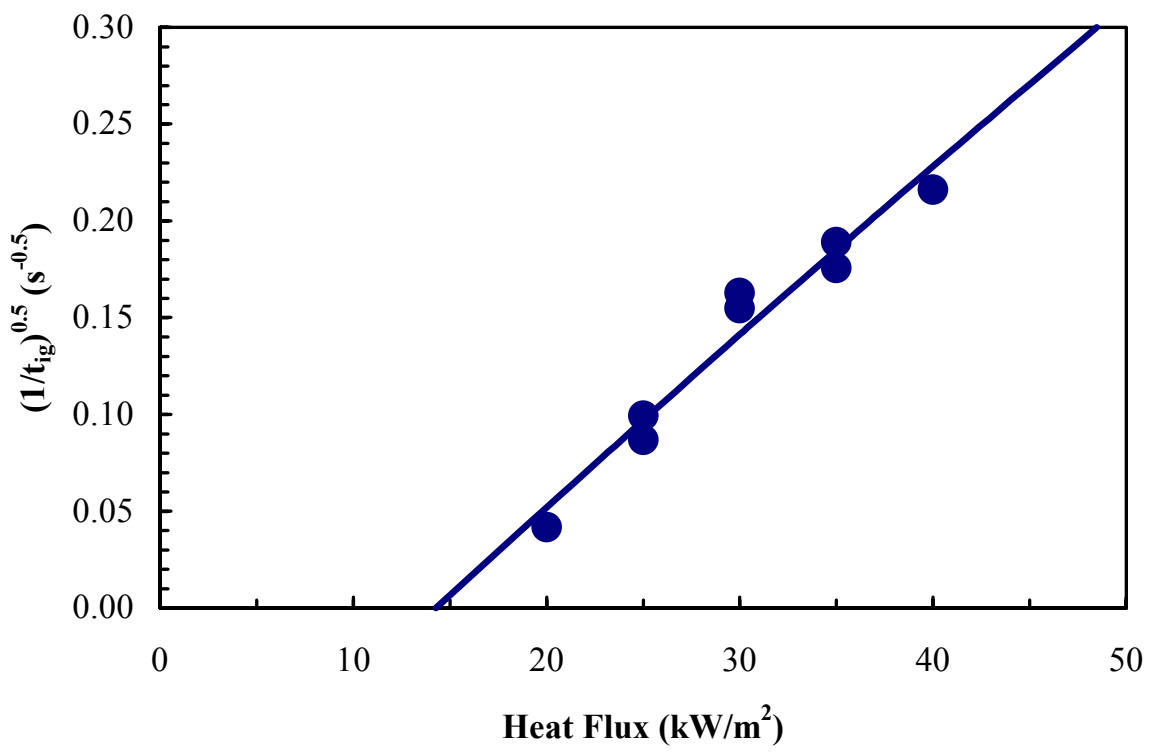

Fig. 4. Correlation of piloted ignition data for redwood 


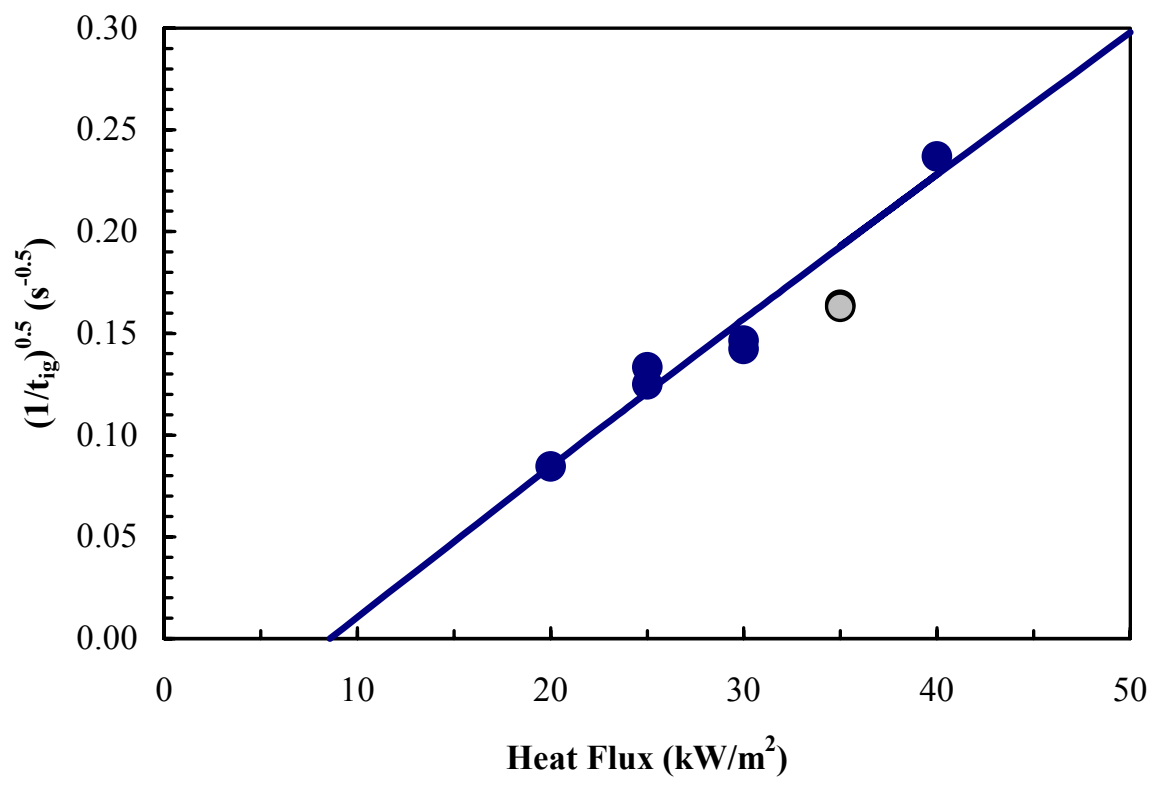

Fig. 5. Correlation of ignition data for radiata pine

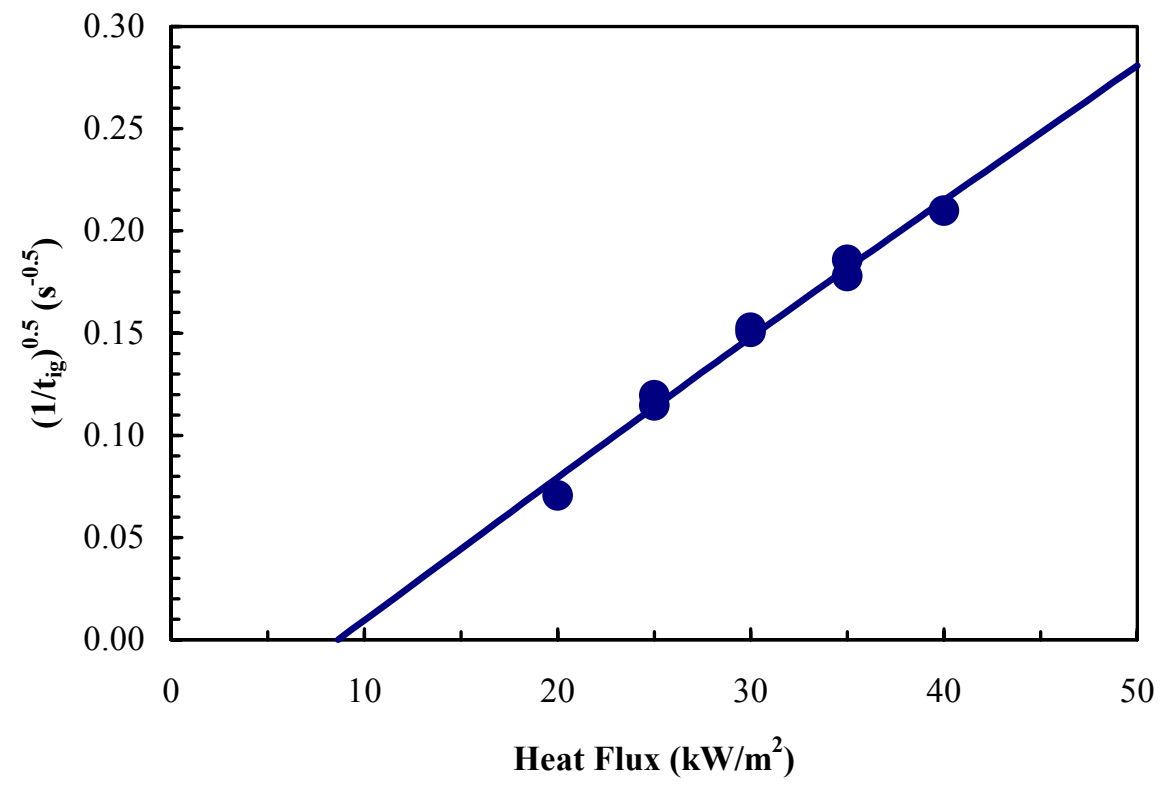

Fig. 6. Correlation of ignition data for Douglas fir 


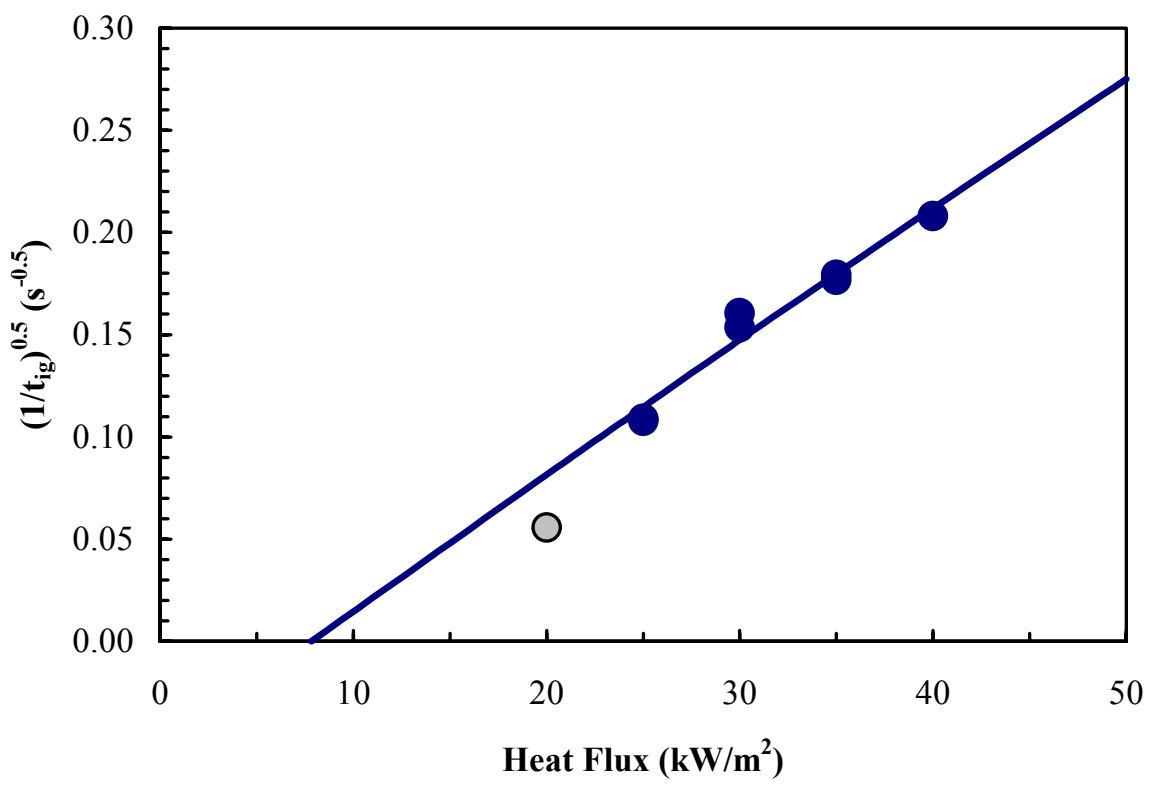

Fig. 7. Correlation of ignition data for Victorian ash

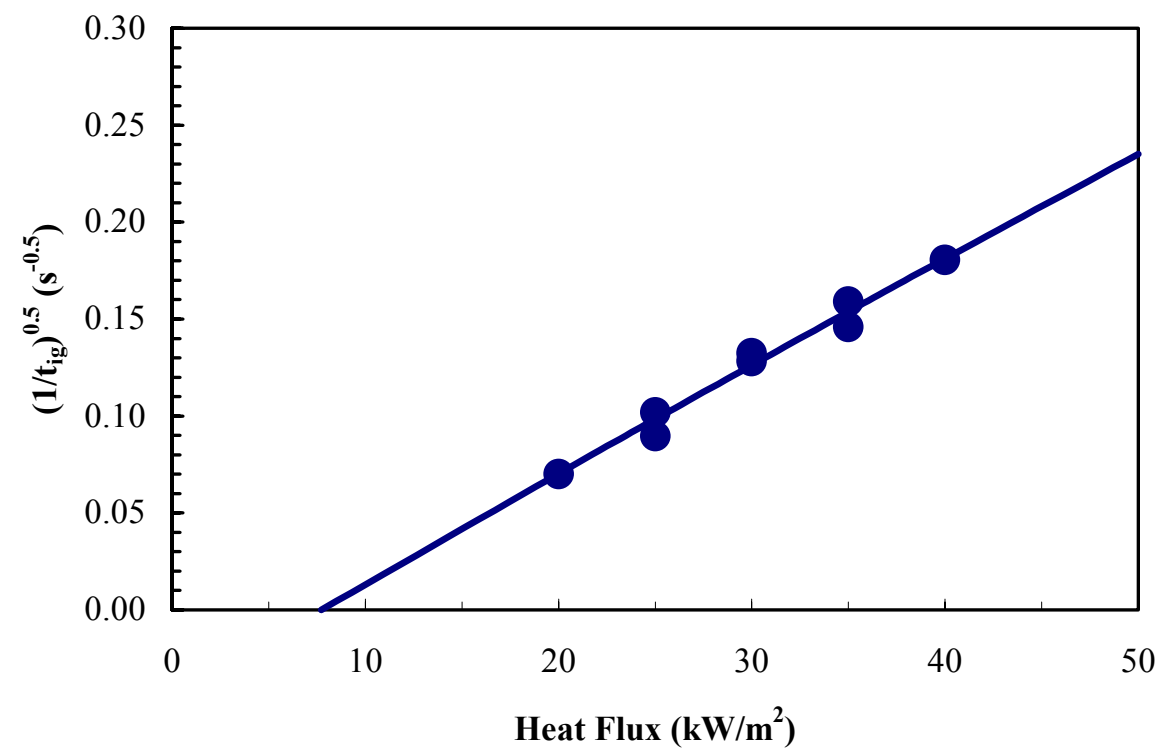

Fig. 8. Correlation of ignition data for Blackbutt 
Table 3. Resulting ignition properties

\begin{tabular}{|c|c|c|c|c|c|}
\hline Species & $\begin{array}{c}\mathrm{T}_{\mathrm{ig}} \\
\left({ }^{\circ} \mathrm{C}\right)\end{array}$ & $\begin{array}{c}\text { Measured } T_{i g} \\
\left({ }^{\circ} \mathrm{C}\right)\end{array}$ & $\begin{array}{c}\dot{q}_{c r}^{\prime \prime} \\
\left(\mathbf{k W} / \mathbf{m}^{2}\right)\end{array}$ & $\begin{array}{c}k \rho c \\
\left(k W^{2} \cdot s / m^{4} \cdot K^{2}\right)\end{array}$ & $\begin{array}{c}\text { Literature } k \rho c \\
\left(\mathrm{~kW}^{2} \cdot \mathrm{s} / \mathrm{m}^{4} \cdot \mathrm{K}^{2}\right)\end{array}$ \\
\hline Western red cedar & 399 & $338-358$ & 12.0 & 0.075 & 0.101 \\
\hline Redwood & 426 & $358-394$ & 14.3 & 0.091 & 0.169 \\
\hline Radiata pine & 349 & 349 & 8.6 & 0.220 & 0.162 \\
\hline Douglas fir & 350 & $349-369$ & 8.6 & 0.245 & 0.166 \\
\hline Victorian ash & 336 & $337-346$ & 7.8 & 0.293 & 0.288 \\
\hline Blackbutt & 334 & $314-352$ & 7.7 & 0.409 & 0.444 \\
\hline
\end{tabular}

\section{DISCUSSION}

The derived ignition temperatures for western red cedar and redwood are higher than the maximum measured temperatures. This discrepancy could be due to measurement errors because it is very difficult to accurately measure surface temperatures with thermocouples. The derived temperatures are within the lower half of the measured range for the remaining four species.

The critical heat fluxes are generally lower than previously reported values. This is due to the fact that convective heat losses are very low at low incident heat fluxes due to the functional relationship between the convection coefficient and the incident heat flux.

Derived and literature $k \rho c$ values are not in very good quantitative agreement. There is some degree of correlation between derived $k \rho c$ values and the densities reported in Table 1. One could re-analyze the ignition data and assume that the thermal inertia is equal to the literature value at $\left(T_{\infty}+T_{\mathrm{ig}}\right) / 2$. The results are presented in Table 4 . The recalculated softwood ignition temperatures generally exceed the measured range, except for redwood. The hardwood temperatures, however, are consistent with the measurements. The critical heat fluxes are still lower than previously reported for reasons explained in the previous paragraph. Overall, the data in Table 4 are more consistent and in better agreement with previous work. This partly supports the hypothesis concerning the $k \rho c$.

\section{CONCLUSIONS}

It is shown that the convection coefficient $\left(h_{\mathrm{c}}\right)$ for a vertical sample prior to ignition in the Cone Calorimeter can be expressed as a quadratic function of the incident heat flux $\left(\dot{q}_{e}^{\prime \prime}\right)$. A procedure to analyze piloted ignition data in terms of material properties was revised to account for the heat-flux-dependent $h_{\mathrm{c}}$. Application of the revised procedure to ignition data for six solid wood species results in a critical heat flux $\left(\dot{q}_{c r}^{\prime \prime}\right)$ that is consistently lower than previously reported. The corresponding ignition temperatures $\left(T_{\mathrm{ig}}\right)$ exceed the measured range for western red cedar and redwood, and are within the lower half of that range for the remaining four species. The conclusion from earlier work that the thermal inertia derived from ignition data for solid wood corresponds to a temperature halfway between ignition and ambient temperatures is only partly supported by the present analysis. The $h_{\mathrm{c}}$ measurements must be verified, and the analysis must be applied to more materials to confirm and extend its validity. 
Table 4. Ignition properties based on literature $k \rho c$ values

\begin{tabular}{|l|c|c|c|c|}
\hline Species & $\begin{array}{c}\mathbf{T}_{\mathbf{i g}} \\
\left({ }^{\circ} \mathbf{C}\right)\end{array}$ & $\begin{array}{c}\text { Measured } \mathbf{T}_{\text {ig }} \\
\left({ }^{\circ} \mathbf{C}\right)\end{array}$ & $\begin{array}{c}\dot{\boldsymbol{q}}_{\boldsymbol{c} \boldsymbol{c r}}^{\prime \prime} \\
\left(\mathbf{k W} / \mathbf{m}^{\mathbf{2}}\right)\end{array}$ & $\begin{array}{c}\text { Literature } \boldsymbol{k} \rho \boldsymbol{c} \\
\left(\mathbf{k W} \mathbf{W}^{\mathbf{2}} \cdot \mathbf{s} / \mathbf{m}^{\mathbf{4}} \cdot \mathbf{K}^{\mathbf{2}} \mathbf{)}\right.\end{array}$ \\
\hline Western red cedar & 382 & $338-358$ & 10.7 & 0.097 \\
Redwood & 389 & $358-394$ & 11.3 & 0.157 \\
Radiata pine & 376 & 349 & 10.6 & 0.172 \\
Douglas fir & 376 & $349-369$ & 10.3 & 0.176 \\
Victorian ash & 339 & $337-346$ & 8.1 & 0.290 \\
Blackbutt & 328 & $314-352$ & 7.4 & 0.438 \\
\hline
\end{tabular}

\section{REFERENCES}

1. ASTM E 1354, "Standard Test Method for Heat and Visible Smoke Release Rates Using an Oxygen Consumption Calorimeter", Annual Book of Standards, Vol. 04.07, American Society of Testing and Materials, West Conshohocken, PA.

2. Janssens, M.L., "Thermal Model for Piloted Ignition of Wood Including Variable Thermophysical Properties," Fire Safety Science -- Proceedings of the Third International Symposium, International Association of Fire Safety Science, Elsevier Applied Science, New York, 1991, pp. 167-176.

3. Janssens, M.L, Dillon, S.E., and Allwein, S., "Characterizing the Thermal Environment of the Cone Calorimeter for Analyzing Ignition Data of Materials," Interflam 2001， $9^{\text {th }}$ International Fire Science \& Engineering Conference, Interscience Communications, London, UK, 2001, pp. 125-135.

4. Janssens, M.L., Thermophysical Properties of Wood and their Role in Enclosure Fire Growth, Ph.D. Thesis, University of Ghent, Ghent, Belgium, 1991.

5. Atreya, A., "Convection Heat Transfer," The SFPE Handbook of Fire Protection Engineering ( $2^{\text {nd }} e d$ ), Society of Fire Protection Engineers, Boston, MA, 1995, pp. 1/39-1/64.

6. Grenier, A., and Janssens, M.L., "Improved Method for Analyzing Ignition Data of Composites," $23^{\text {rd }}$ International Conference on Fire Safety, Product Safety Corporation, Sunnyvale, CA, 1997, pp. 253-264.

7. Maku, T., "Studies of the Heat Conduction in Wood," Wood Research Bulletin, Wood Research Institute, Kyoto, Japan, 13:180 (1954).

8. MacLean, J., "Thermal Conductivity of Wood," Transactions of the American Society of Heating and Ventilation Engineers, 13:380-391 (1941).

9. Koch, "Specific Heat of Oven Dry Spruce, Pine Wood and Bark," Wood Science, 1:203-214 (1969). 